\title{
Scientific Associations as Communities of Practice for Fostering Collaborative Knowledge Building: Case Study of IAKM
}

\author{
Meliha Handzic ${ }^{1}$, Constantin Bratianu ${ }^{2}$ and Ettore Bolisani ${ }^{3}$ \\ ${ }^{1}$ International Burch University, Sarajevo, Bosnia and Herzegovina \\ ${ }^{2}$ Bucharest University of Economic Studies, Bucharest, Romania \\ ${ }^{3}$ DTG - University of Padova, Vicenza, Italy \\ meliha.handzic@ibu.edu.ba \\ constantin.bratianu@gmail.com \\ ettore.bolisani@unipd.it
}

\begin{abstract}
Knowledge building is a social process that is driven by the willingness of people to share their expertise and create new knowledge. Scientific Communities of Practice (CoPs) are communities of professors and researchers whose aim is to foster scientific knowledge generation. In the KM literature, research concerning this kind of CoPs has been substantially neglected so far. The present research analyses the case study of the International Association for Knowledge Management (IAKM) seen as a scientific CoP where members are mostly academics with research interests in developing and promoting knowledge management. Based on a collection of quantitative and qualitative data about member collaborations and scientific production, the study investigates the structure of interactions and the collaborative processes of IAKM members and the specific mechanisms of knowledge building within this CoP, seen as a paradigmatic example of scientific community. Members were asked to respond to a survey regarding their collaborative activities carried out with other IAKM members in the period of $2011-2020$. The descriptive analysis revealed the kind of collaborations, the distribution of interactions across the community, and the dynamic patterns over time. A follow-up social network analysis was used to provide deeper insight into the community structure and dynamics. The research found that a CoP can really be useful for progress in a scientific field because it can provide a platform for trust and mutual acquaintance that reduces barriers to collaboration and knowledge building across different universities, professional roles, countries, and cultures, which is increasingly important for the progress of science. Most importantly, IAKM exhibited a cohesive and active core membership with pivotal roles played by a number of active members, which contributed significantly to the growth of the Association and, in general, to the advancements in the field of KM through collaborative knowledge building.
\end{abstract}

Keywords: collaborative knowledge building, knowledge sharing, scientific community of practice, social network analysis, case study

\section{Introduction}

Knowledge building is a process of production of knowledge by means of continual improvement of ideas that have a value for a community (Scardamalia and Bereiter, 2003). As Jakubik remarks "knowledge is embedded in human relations and it is created in a heuristic process when individuals interact in a social context" (Jakubik, 2008, p. 6). Therefore, knowledge building is substantially a process of "collaborative knowledge building", in other words it is a concept that reflects a constructivist perspective on social knowledge generation (Gilbert \& Driscoll, 2002; Hmelo-Silver, 2003; Hmelo-Silver \& Barrows, 2008; Putambekar, 2006).

Indeed, the source of any knowledge, that becomes a seed for knowledge building, is an individual's mind. However, while knowledge is born in the body and the mind of an individual, when it is shared in a network of social relationships it becomes a subject of collective restructuring and developing. Knowledge becomes a dynamic entity which stems from the contributions of those who participate at a given time in a certain social context.

The characteristics of this social context clearly influence the process of collaborative knowledge building. Its effectiveness can depend on the attitude or motivation of each participant to share his/her experience and expertise, or on the psychological or trust climate that exists (Hardwick et al., 2013). Also, it can be influenced by the structure of interactions and networking patterns that develop between participants (Philip, 2010), or by the mechanisms and tools that are used for sharing knowledge.

A popular organizational context often analysed in knowledge management (KM) is the Community of Practice (CoP), a "group of people who share a concern, a set of problems, or a passion about a topic, and who deepen 
their knowledge and expertise in this area by interacting on an ongoing basis" (Wenger et al., 2002, p. 4). CoPs are environments where the processes of collaborative knowledge building can develop effectively (Alamantariotou et al., 2014).

A particular context for collaborative knowledge is scientific research. Here, a proper balance must be found between richness of diversity in specialisations on the one hand, and commonality of interests and existence of a common ground for effective communication on the other hand. (Guimerà et al., 2005). Scientific Associations are a particular example of CoPs in science, involving scholars who share a scientific interest but work in different scientific institutions.

Indeed, as the tragedy of the COVID pandemic clearly shows (Hensher et al., 2020), there is (and there has probably always been) a need for scientists to cooperate freely all around the world. For this reason and, in addition, considering that the mechanisms and structures of scientific associations as CoPs have been more rarely analysed in the KM literature, the goal of this paper is to provide insights into this topic by means of a study of the case of the International Association for Knowledge Management (IAKM).

The purpose is to shed light into the structural conditions and enabling mechanisms that can favour collaborative knowledge building in scientific CoPs. An empirical analysis of IAKM members' engagement in collaborative knowledge building processes is performed. Based on data collected by means of a questionnaire survey, the structure of interactions and cooperations has been framed. In addition, a content analysis of IAKM's main publication outlets has been conducted, to gain a better insight into the nature of the community's knowledge building outcomes.

This analysis aims at revealing how collaborative knowledge building can really develop within a Scientific Community of Practice when there are appropriate conditions that favour fruitful knowledge exchanges. It is also intended to provide support to the argument that, while knowledge remains the result of a cognitive process of individuals, a proper organisational setting can play a vital role in amplifying the creation of new knowledge in science through collaboration. Finally, we examined whether and how collaboration processes in a CoP can be facilitated by the existence of active and pivotal members that can attract and boost interpersonal interactions with other members, and to what extent these mechanisms are driven by the formal organisation.

The structure of the paper is as follows: the second section recalls the main literature references, and section 3 presents IAKM as a Scientific Community of Practice; section 4 describes the empirical methodology and section 5 the main results. Section 6 (Discussion) and 7 (Conclusion) highlight the main contributions of the study.

\section{Literature review}

Scardamalia and Bereiter (2003) define knowledge building "as the production and continual improvement of ideas of value to a community, through means that increase the likelihood that the community accomplishes will be greater than the sum of individual contributions and part of broader cultural efforts" (p. 1370). The authors underline the importance of a social synergy requested by the nonlinearity of the knowledge building process, and of the cultural environment. This leads to the notion of collaborative knowledge building, a generic concept for all the processes of knowledge creation based on the assumption that knowledge is a complex construct that involves both individual minds and social contexts (Hmelo-Silver, 2003; Kali, 2006; Scardamilia \& Bereiter, 2006; Singh et al., 2007).

Social knowledge is a dynamic result of the contributions of the many who take a part in this and, therefore, can depend on various elements that pertain to the individual or to the social group. It is enabled by the motivation of each participant to share his/her experience and expertise in a certain activity domain, but that motivation can be stimulated or inhibited by the psychological climate in the given social context, because knowledge sharing may lead to either a winning or a losing game. Trust and a certain learning interest are additional factors that can affect an effective attitude towards knowledge sharing and, by this means, collaborative knowledge building.

There are several models describing this social construction and explaining knowledge dynamics (Nissen, 2006; Nonaka \& Takeuchi, 1995; Nonaka et al., 2008; Stacey, 2001). As Wenger et al. remark, "What managers have 
been missing so far is an understanding of the kind of social structure that can take responsibility for fostering learning, developing competencies, and managing knowledge" (Wenger et al., 2002, p. 11).

A comprehensive model was conceived, among the first researchers, by Nonaka (1994), developed then by Nonaka and Takeuchi (1995), and revisited with upgrades by Nonaka and Takeuchi (2019). In the first version, the knowledge creating dynamic model had two dimensions: epistemology and ontology. In this model, knowledge is broadly defined "as a justified true belief that is created and practiced by people, through their interactions with others and the environment, and in a specific situation or concept" (Nonaka \& Takeuchi, 2019, p. 60). The metaphor used by these authors for understanding knowledge is the iceberg. The visible part of the iceberg that is situated above the water surface refers to the explicit knowledge, and the hidden part of the iceberg that is covered by the water the tacit knowledge. The SECl model contains four basic processes: Socialisation (S), Externalisation (E), Combination (C), and Internalisation (I). Socialisation contains tacit knowledge - tacit knowledge sharing within the social context, externalisation contains tacit knowledge explicit knowledge conversion at the individual level, combination refers to explicit knowledge - explicit knowledge building up within the social context, and internalisation refers to explicit knowledge - tacit knowledge conversion at the individual level (Nonaka \& Takeuchi, 1995; Nonaka et al., 2008). Externalisation that reflects articulating explicit knowledge and internalisation that reflects embodying tacit knowledge develop along the epistemological dimension. Socialisation that reflects empathising with people through tacit knowledge and combination that reflects the social connecting and interaction through explicit knowledge develop along the ontological dimension (Nonaka \& Takeuchi, 1995; Nonaka et al., 2008). Thus, knowledge is built up ontologically from the individual to the team, then to the organisation, and finally to the community.

In their revisited SECI model Nonaka and Takeuchi (2019) introduce time as an explicit dimension, such that knowledge building becomes a three-dimensional process looking like a spiral. "The SECI Spiral occurs as knowledge creation is carried out repeatedly over time. In essence, the SECI Spiral is an extension of the SECI process in which knowledge is ceaselessly created, amplified, and practiced, and more knowledge that is created and disseminated is converted into action" (Nonaka \& Takeuchi, 2019, p. 71). The authors integrate knowledge creation with knowledge practice revealing the role of phronesis or practical wisdom in decision-making. Metaphorically, knowledge creation and knowledge practice look like the two sides of the same coin. This feature of the SECI Spiral model reflects very well the knowledge building process within CoPs, especially within the scientific CoPs like IAKM.

In the model proposed by Nissen (2006) the focus is on knowledge flow. Changing the metaphor used in the first phase of knowledge management (Andriessen, 2008), from physical objects to fluid flows, Nissen shows how knowledge is building up within a social context: "To the extent that organisational knowledge does not exist in the form needed for application or at the place and time required to enable work performance, then it must flow from how it exists and where it is located to how and where it is needed. This is the concept knowledge flows" (Nissen, 2006, p. xx). The SECI Spiral and the knowledge flows models can be integrated in practice (Nonaka et al., 2008).

Going beyond Nonaka and Takeuchi $(1995,2019)$, and Nissen (2006), Bratianu and Bejinaru (2019, 2020) introduce the energy metaphor and a thermodynamics approach in conceptualising knowledge transformation and knowledge building within social contexts. According to their model, there are three fundamental fields of knowledge: rational, emotional, and spiritual. Rational knowledge is the result of our rational thinking and it is expressed as explicit knowledge. Emotional knowledge reflects the wordless knowledge generating within our body as a result of the experiential learning. Emotional learning is processed by emotional intelligence that is an important component of the social intelligence (Goleman, 2007; Kahneman, 2011). Spiritual knowledge reflects our beliefs and values which influence the decision-making process (Nonaka \& Takeuchi, 1995; Zohar \& Marshall, 2004). It is processed by the spiritual intelligence, which together with emotional intelligence determines the behaviour and adaptation capacity of people within social contexts. Thus, the knowledge building process along the ontological dimension can be better explained if one considers the contribution of rational intelligence, emotional intelligence, and spiritual intelligence, which act interactively and iteratively (Briskin et al., 2009; Goleman, 2007).

All of the models above show that there are some organisational settings, intentionally designed, where people overcome the emotional barriers in developing mutual relationships more easily and reach a shared understanding more efficiently, which results from the community shared values (Ali et al., 2019; Nahyan et al., 
2019; O’Dell \& Hubert, 2011; Stahl, 2000; Wenger, 1998). In these contexts, collaborative knowledge building is a complex process that can also be well-supported by an appropriate IT infrastructure (Chee, 1996; Li, 2006; O’Dell \& Hubert, 2011).

Those groups of people where trust and shared learning interests have a stimulating role in knowledge sharing and building, tend to develop a certain identity and gravity force in time. This is exactly what characterises a Communities of Practice (CoP). According to Wenger et al., "Communities of practice are groups of people who share a concern, a set of problems, or a passion about a topic, and who deepen their knowledge and expertise in this area by interacting on an ongoing basis" (Wenger et al., 2002, p. 4). CoPs may have a name or not, a formal status or not, a well-defined boundary or not, a management team or not, but nonetheless their common characteristic is their stimulating role in knowledge sharing and knowledge building due to a shared set of values accepted by all members (Bolisani \& Bratianu, 2018; Wenger et al., 2002).

Therefore, CoPs can be regarded as an environment where processes of collaborative knowledge building can occur and be nurtured (Alamantariotou et al., 2014). Their effectiveness depends on a set of conditions and characteristics of i.e.: a) the social, psychological, and trustworthy context that can influence members' active participation and willingness to share experience and expertise (Hardwick et al., 2013); b) the dynamics of networking, interactions, and the kind of knowledge exchanges (Liu et al., 2005); c) the emerging structures and pivotal nodes that can play an essential role in stimulating interactions in the whole group (Oshima et al., 2012; Philip, 2010), and d) the tools that are used for sharing knowledge (Alamantariotou et al., 2014).

A particular context where collaborative knowledge building develops in peculiar forms is scientific research. Here, there is a need to incorporate individuals with different ideas, skills and resources: indeed, creativity often develops when innovations are introduced into new domains, for solving new problems and inspiring fresh thinking. But it is also necessary that a proper balance is found between diversity - which may potentially spur creativity but can also lead to conflict and miscommunication (Guimerà et al., 2005) - and homogeneity - which favors knowledge sharing but reduces the space of innovations. Scientific Associations can be a particular kind of CoP where collaborative knowledge building can occur between scholars who share a discipline or research field but also work in different institutions. In addition, scientific CoPs generally gather people not only of different specialisations but also cultures. This is particularly important to consider, because designing collaborative knowledge building environments should use an integral or integrative approach (Kirman et al., 2011; Murray, 2006; So et al., 2010) and incorporate cultural dimensions when CoP members come from different cultures. Many intercultural projects failed so far because they ignored these cultural dimensions which integrate emotional and spiritual knowledge (Haig, 2003; Hong et al., 2010).

Although in the KM literature there are many examples of CoP, there is a scarcity of papers focusing on Scientific Associations as CoPs. Their mechanisms and structures - and the knowledge dynamics that occur in them - have been rarely analysed. Filling this gap is the main goal of this paper.

\section{The case study: IAKM as a Scientific CoP}

In this section we will focus specifically on three main points: first, what a scientific association is; second, if a scientific association can be considered as a CoP and under what conditions; third, if IAKM - which is our case study - can be considered a CoP.

In regards to our first point, it can be easily affirmed that Scientific Associations have a long history (Eamon \& Paheau, 1984) that can be traced back at least to the 16th century when the "Academia Secretorum Naturae (Accademia dei Segreti)" was founded in Naples by the mathematician Giambattista Della Porta. In these associations, scholars "looked for a more satisfactory intellectual environment outside the walls of the university, seeking protection and patronage from rulers who hoped to enhance their own prestige as benefactors of the new learning"; these societies "fostered the idea of cooperative scientific effort and became centres for the dissemination of scientific information" (Eamon \& Paheau, 1984). In short, Scientific Associations became communities where scholars shared a common interest and sought for mutual cooperation, with the purpose of enhancing scientific knowledge. They rapidly acquired a key role in the development and dissemination of scientific knowledge not only in $t$ academia but, more broadly, in societies. There are some paradigmatic examples like the UK's Royal Society (www.royalsociety.org) which clearly show this. 
Over the centuries, a lot of Scientific Associations were created with similar characteristics, as a forum of independent scholars who share an interest in a branch of science and seek for collaboration beyond the limits of their respective organisations, universities, and nations. Scientific Associations have been created in all areas of science. They may have different structures and operative mechanisms, but they all share the original features and goals (maybe declined in a more modern language), e.g.: favouring the development of a scientific discipline, consolidating its academic or professional recognition, facilitating the connection between scholars of different organisations, organising workshops and conferences, editing publications, providing reference to younger researchers, designing and maintaining websites, mailing lists, and document repositories, etc.

Can a Scientific Association be considered a "CoP" the way this notion is generally defined? As mentioned, in KM, the term was introduced by Wenger and colleagues (Lave and Wenger, 1991; Wenger et al., 2002) and, if we examine the literature, this concept has been applied in different ways (Bolisani \& Scarso, 2014). Nevertheless, the practical implementations (in companies, public organisations, or even across organisations) often have some common characteristics: they can include amateurs as members, but are generally targeted to experts or professionals in a knowledge domain; they often are, to some extent, deliberately planned, but have some light "management structure", whose purpose is mainly to set the general rules of interpersonal interactions (for example, to guarantee a "democratic" debate), to facilitate people's knowledge exchange, and to manage some service activities for the benefit of their members (for example, running a communication system, organising virtual or in-person workshops, etc.). As for Scientific Associations, although there is little or no sign of studies that analyse them as CoPs, if we consider the notion of Scientific Association that we mentioned above it can be easily concluded that these organisations are, indeed, CoPs - even if their Statutes and formal/informal documents never mention this term. Indeed, a Scientific Association is created to facilitate the exchange of knowledge of its members; it focuses on a particular subject, discipline, or domain; it collects people that have some professional interest in it; and it has a "management group" whose goal is to favour interactions of members for the benefit of the whole Association (and, secondly, of the public). All this well fits the definition of CoP and the characteristics that are generally ascribed to it, as was mentioned earlier.

Finally, considering IAKM, this is a non-profit organisation designed to promote KM and to contribute through its members to the advancement of knowledge about managing knowledge and wisdom (see www.iakm.net for details and supporting documentation). IAKM has a well-defined membership, a legal statute, and declared mission to stimulate collaborative knowledge building among its members and a flow of knowledge towards other academic communities, societies, and business environments. The great majority of members are university professors and researchers (although there are also some business professionals in the group), and they share the same willingness for learning and knowledge building, as well as its dissemination through specialised journals, books, conferences, exchange programs, doctoral boards, and many other activities (Bolisani \& Handzic, 2015; Bolisani \& Bratianu, 2018; Bratianu, 2014; Petrides \& Nodine, 2003).

Its history and development show that this organisation is, indeed, a CoP even though this term has never been used explicitly in the official papers. IAKM was initiated in 2011 and formally founded in 2012 by 11 scholars of various universities; it progressively grew and now it reaches around 80 members, internationally spread: all members share a common interest in a scientific domain (i.e.: knowledge management) and this interest is substantially professional - because members are scientists whose research area is KM, or practitioners that work in the field. The Association has a light management structure (a Board, a President, and occasional service roles) whose main goal is to facilitate interactions of members - without restrictions due to different career position, age, or scientific recognition, to promote open debate in hot topics for the discipline, to favour the sharing of information about opportunities for research in the field, and to promote all possible forms of dissemination of the scientific results obtained by any member. All these issues - that are, by the way, typical of any Scientific Association - are also characteristics of a CoP as we defined it earlier.

IAKM typically pursues its goals with a mix of formal activities and informal initiatives: on the one hand, IAKM workshops and meetings are organised regularly for the benefit of members that can share information and opinions about their respective work; in addition, the Association promotes a Book Series where all members are invited to cooperate as authors, editors, or reviewers. But all this is gained through active participation and volunteering: regardless of the (light) formal activities and roles that IAKM, as any other scientific Association, has, it is mainly an "informal container" that gives the opportunity to members to reinforce their interpersonal knowledge and, in this way, to create opportunities of cooperative scientific work in the form of joint projects, 
publications, invitations to seminars and conferences, etc. A website, an email newsletter, and a Youtube channel are the digital platforms also used to exchange materials and disseminate information to the public.

\section{Research methodology}

Case studies are considered particularly suitable for exploring community-based problems as they enable researchers to examine social and behavioural questions in real-life contexts and rely on multiple quantitative and qualitative data analyses (Yin 1994). Hence, this was our preferred choice of a research method for the current investigation. Specifically, an empirical analysis of IAKM members was conducted with the purpose of investigating the mechanisms and structures of this CoP and how these have favoured the processes of collective knowledge building. These were the specific goals: a) reconstructing the networks and intensity of interactions and collaborations that IAKM members developed over time; b) identifying structural patterns and pivotal roles in these networks; c) examining the types of collaboration, and d) analysing the production of collaborative knowledge in the form of produced publications. A combined approach including a quantitative IAKM membership survey followed by a qualitative IAKM publications' analysis (i.e., the main outcomes of collaborative knowledge building in science) was adopted to enable better understanding of key concepts.

All IAKM members were invited to provide a synthesis of their contributions to the main processes of knowledge building and insert them into a certain framework. Data collection was carried out in January 2020. Specifically, members were asked to fill in a questionnaire form distributed by email. Then all their inputs were analysed by using some specialised software for social network analysis, and the results were graphed and interpreted. In addition, content analysis of IAKM's main publication outlets was conducted to gain a better insight into the nature of the community's knowledge building contributions. In this way, it was possible to produce a broad picture of IAKM's collaborative knowledge development since its initiation in 2011 to date.

The questionnaire written in a MS Excel sheet included the following questions: (a) names of all collaborating members, (b) type of collaboration (e.g., joint publication or event), (c) year and (d) short description. Joint publications covered journal articles, conference papers, books, book chapters, presentations etc. Joint events covered panels, workshops, forums, conferences, special tracks/sessions, projects etc.

Subjects for this research were all members of IAKM whose name was in the official records of the Association. The questionnaires were distributed to the recipients by email together with a short explanatory statement about the study aim and instructions for completing the survey. Data collection lasted one month. A total of 19 responses were received from 76 questionnaires distributed, reporting a total of 50 different collaborating members from around the world.

The collected responses were combined in one MS Excel sheet. They were cross-checked and duplicates were eliminated from further analysis. In addition, various reported collaborative activities were classified into research, teaching and professional support categories. Then, relevant descriptive statistics were calculated and presented visually using three different software programs (MS Excel, Palladio and Gephi).

This quantitative analysis was further supplemented by a qualitative content analysis of a selection of publications produced by IAKM members. This selection is based on the book series "Knowledge Management and Organisational Learning" (https://www.springer.com/series/11850), which is the official book series of the Association and where there are a lot of contributors of the various members. This can help to build a significant picture of the results of collaborations by singling out some key contributions to knowledge production in IAKM. The results obtained from both types of analysis are described in the following section.

\section{Results}

An initial analysis of the collected data revealed that a two-third majority (66\%, 50 out of 76 ) of the IAKM membership collaborated in one or more research, teaching or professional support activities over the past decade. Collaborators spread over 25 different countries from 5 different continents. These were more prominent in Europe (as visible in Figure 1), which well reflects the statistical composition of the current IAKM membership, where the major part is compounded by Europeans. 


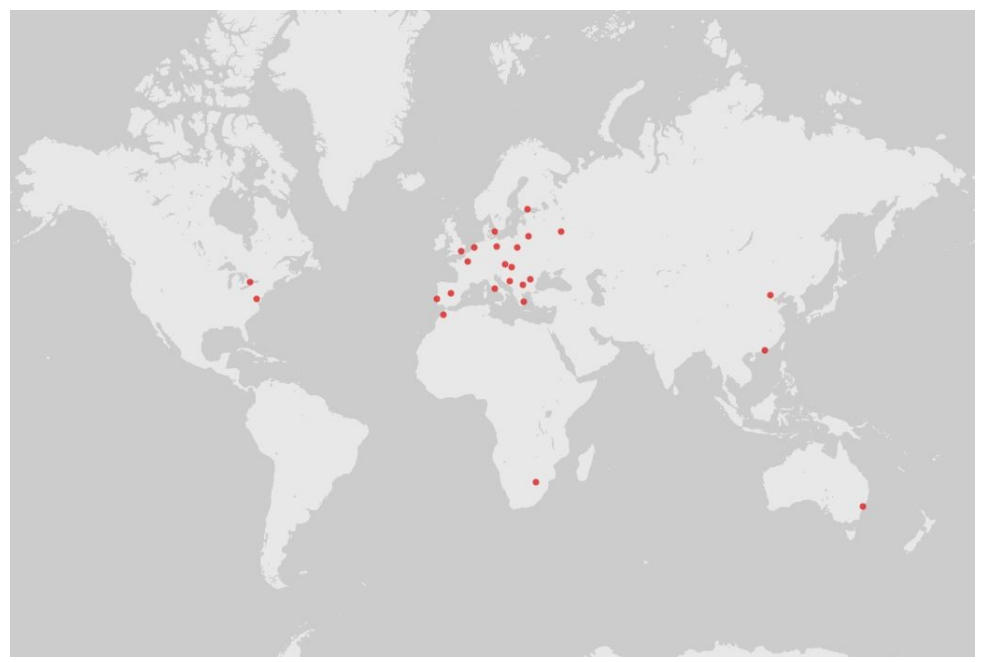

Figure 1: Geographic distribution of collaborating members

The number of members who collaborated in different activities varied from 2 to 21 as shown in Figure 2. Typically, collaborative activities involved only 2 members (113), followed by 3 members (28) and 4 members (19). Larger groups of 5, 6, 7 and 8 members were less frequent $(7,8,7$ and 3 activities respectively). One group of 12 members was involved in 2 activities, while three groups of 11,13 and 21 members collaborated in 1 activity.

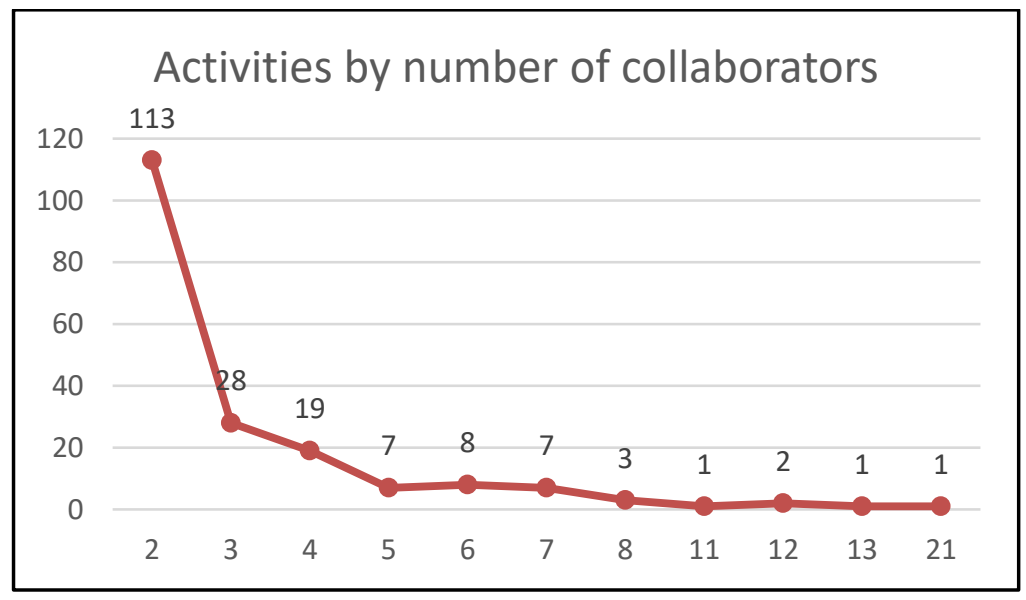

Figure 2: Frequency of collaborative activities by number of collaborators

With respect to the main types of members' collaborative activities, Figure 3 reveals the greatest focus on research. The majority of members (72\%) co-authored conference papers (54) and journal articles (44), followed by books (10), book chapters (4) and other various publications (3). They also participated in various collaborative workshops (8), panels (4) and project applications (4).

Some members (21\%) offered important professional support in terms of jointly organising various communication activities (12), conferences (10) and meetings (3). They also participated in various committees (10) and acted as co-editors of book series (1), journals (1), special journal issues (1). A smaller number of members (7\%) were involved in collaborative teaching activities such as preparing delivering seminars (6) and courses (2), students exchanges (3) and joint theses supervision (1). 


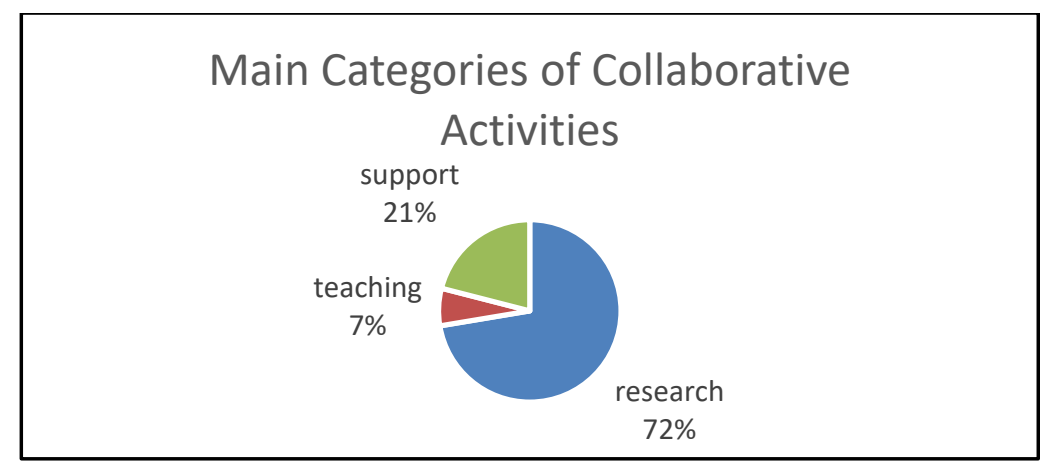

Figure 3: Distribution of main categories of collaborative activities

Results of the trend analysis of members' collaborations over time are presented in Figure 4. The figure shows a steady increase in the number of collaborative activities from 7 to 41 in the period 2011-2018 and a slight decrease from 41 to 32 activities in year 2019. Data for 2020 are incomplete (they refer only to a small part of that year).



Figure 4: Trend in number of members' collaborative activities over time

Deeper analysis of the IAKM dynamics using social network analysis (SNA) discovered a key role of the IAKM'S founding president (id29) in initiating and participating in a wide range of collaborative research, teaching and professional support activities. The results of SNA presented in Figure 5 also show a highly active core group of other 9 members (id27, 19, 3, 59, 45, 25, 7, 54, 12). They represent mostly past or current board members.

Further analysis of the community's structural composition revealed 3 large and 2 small sub-groups. These are presented in Figure 6. With respect to 3 large groups, the figure shows that the largest one (violet nodes) consists of 21 members (id4, 11, 57, 43, 39, 24, 58, 34, 14, 73, 3, 42, 76, 63, 74, 35, 65, 69, 61, 28, 33). Their identities reveal that they come from all around the world. The figure also suggests an important role of one member (id3), in establishing these worldwide relationships. The second large group (green nodes) consists of 15 members. Their identities reveal mostly founding and long-term members (id47, 72, 38, 54, 15, 31, 36, 62, 7, 59, $29,45,27,46,66)$. Here, the role of (id29) is particularly visible in maintaining intensive collaborations with the IAKM's core members. The third large group (blue nodes) has 10 members (id19, 25, 32, 67, 68, 12, 71, 5, 2, 49). According to their identity numbers, these members come predominantly from Romania. One member of this group, the current IAKM's president (id19), plays a visible role in mobilising other members (who are his nationals in the community). With respect to 2 small groups, the first one (orange nodes) is completely isolated and consists of 2 members (id9, 16) from the same institution in China. The second group (black nodes) of 2 members (id8, 13) appears connected to the largest group (violet nodes) and thus may be treated as its integral part. 


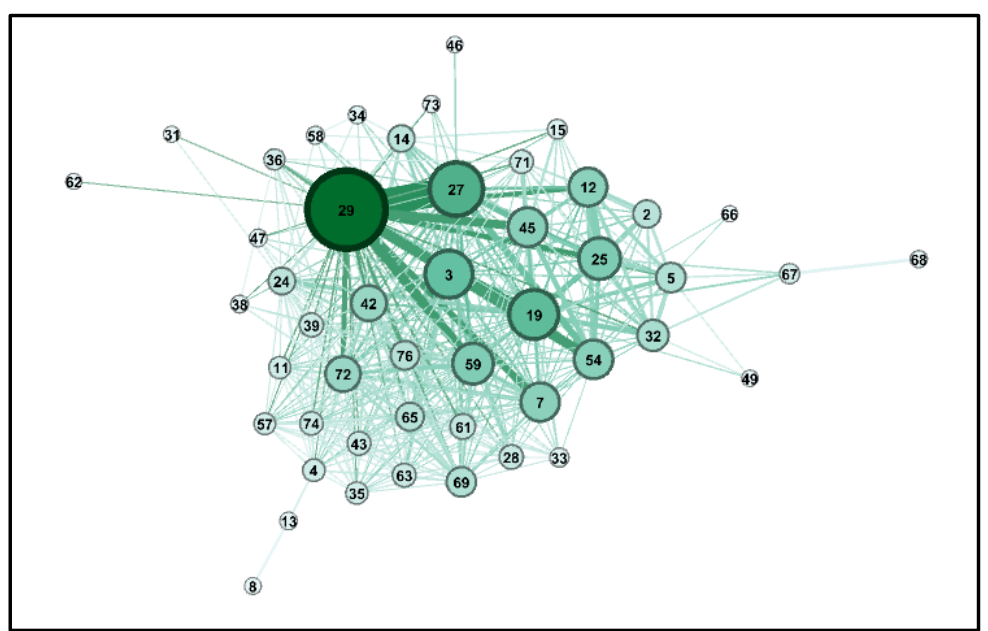

Figure 5: Intensity of community members' collaborations

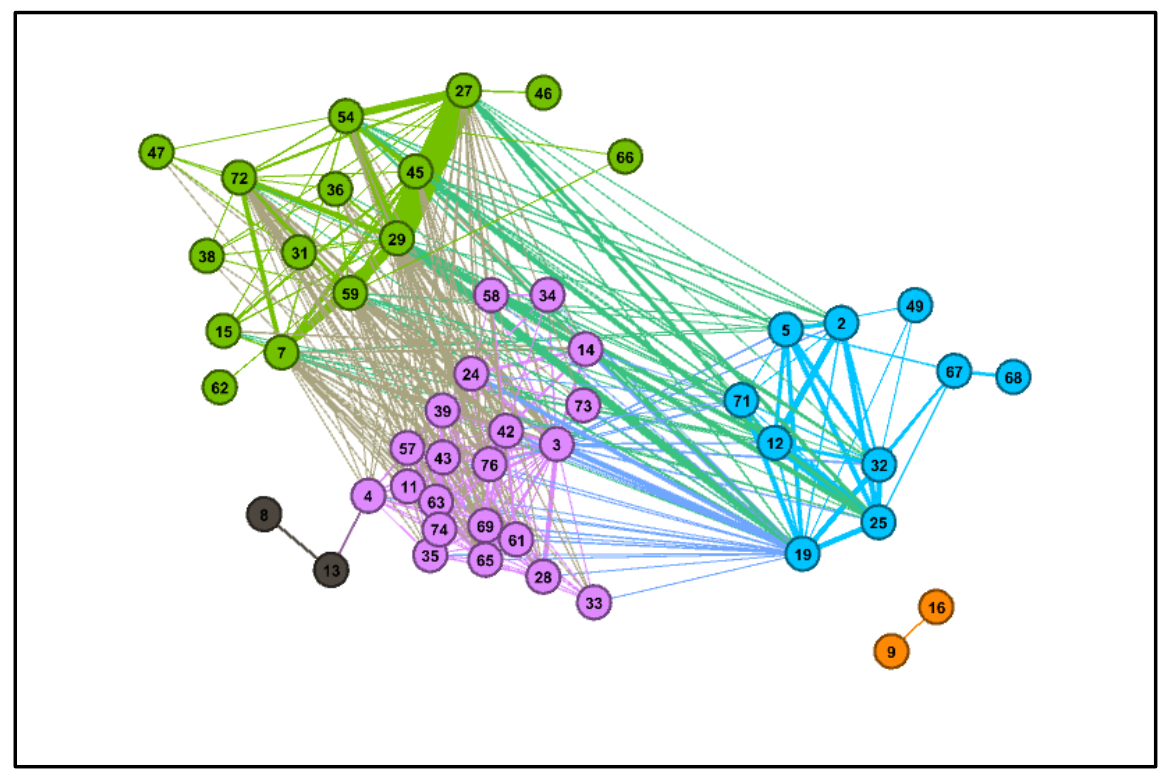

Figure 6: Structural composition of the collaborative community

The results of the qualitative analysis of IAKM's book series Knowledge Management and Organisational Learning $(\mathrm{KMOL})$ are presented in Table 1. The content analysis of KMOL's nine volumes reveals a variety of topics and issues addressed. Two volumes examined the entire KM domain (Vol. 1 \& Vol.4). Another two early volumes addressed two major KM sub-domains, hard technical (Vol 2) and soft social (Vol.3). One volume was dedicated to a particular category of stakeholders within the project KM domain, namely project managers (Vol .5). Finally, several later volumes examined KM in the context of economy (Vol. 6), arts and humanities (Vol.7), education (Vol. 8) and industry (vol. 9).

Table 1: List of titles and characteristics of KMOL series volumes

\begin{tabular}{|l|l|}
\hline Volume & Characteristics \\
\hline $\begin{array}{l}\text { 1.Advances in Knowledge } \\
\text { Management: Celebrating Twenty }\end{array}$ & $\begin{array}{l}\text {-Tracks knowledge management development over two decades } \\
\text {-Provides essential reference to key studies and scholars } \\
\text {-Includes lessons learnt from state-of-the-art KM applications in business, } \\
\text { government, and civil sectors }\end{array}$ \\
\hline $\begin{array}{l}\text { 2.Corporate Knowledge Discovery } \\
\text { and Organisational Learning: The } \\
\text { Role, Importance, and Application } \\
\text { of Semantic Business Process } \\
\text { Management }\end{array}$ & $\begin{array}{l}\text {-Provides a new way to knowledge discovery and extraction from business } \\
\text { processes }\end{array}$ \\
\hline $\begin{array}{l}\text { 3.Social Knowledge Management in } \\
\text { Action: Applications and Challenges }\end{array}$ & -Illustrates three different application cases \\
\hline
\end{tabular}




\begin{tabular}{|c|c|}
\hline Volume & Characteristics \\
\hline & $\begin{array}{l}\text { - New insights on applying social media in organisations } \\
\text { - Selected set of empirical research papers by experts in their field }\end{array}$ \\
\hline $\begin{array}{l}\text { 4.Emergent Knowledge Strategies: } \\
\text { Strategic Thinking in Knowledge } \\
\text { Management }\end{array}$ & $\begin{array}{l}\text { - Fresh perspective on knowledge management and strategic thinking } \\
\text { - New reflections on the emerging domain of knowledge strategies } \\
\text { - Critical analysis of organisational knowledge dynamics }\end{array}$ \\
\hline $\begin{array}{l}\text { 5.Knowledge and Project } \\
\text { Management: A Shared Approach } \\
\text { to Improve Performance }\end{array}$ & $\begin{array}{l}\text { - Offers a fresh perspective on benefits and outcomes of merging Knowledge } \\
\text { and Project Management } \\
\text {-Reviews relevant concepts and models integrating Knowledge and Project } \\
\text { Management } \\
\text { - Unifies art and science of both fields }\end{array}$ \\
\hline $\begin{array}{l}\text { 6. Knowledge Management in the } \\
\text { Sharing Economy: Cross-Sectoral } \\
\text { Insights into the Future of } \\
\text { Competitive Advantage }\end{array}$ & $\begin{array}{l}\text { - Helps readers to achieve insights into the interaction between } \mathrm{KM} \text { and sharing } \\
\text { economy } \\
\text { - Provides cross-sectoral and cross-national approaches to compare and } \\
\text { distinguish industry and country specific nuances } \\
\text { - Addresses both current phenomena and future challenges }\end{array}$ \\
\hline $\begin{array}{l}\text { 7.Knowledge Management, Arts, } \\
\text { and Humanities: Interdisciplinary } \\
\text { Approaches and the Benefits of } \\
\text { Collaboration }\end{array}$ & $\begin{array}{l}\text {-Provides empirical evidence on benefits of cross-breeding KM with arts and } \\
\text { humanities } \\
\text {-Demonstrates how traditional methods from arts and humanities help in } \\
\text { knowledge creation and evolution } \\
\text {-Shows how KM models and practices provide valuable benefits in a digital } \\
\text { environment for these fields }\end{array}$ \\
\hline $\begin{array}{l}\text { 8.Connecting Adult Learning and } \\
\text { Knowledge Management: } \\
\text { Strategies for Learning and Change } \\
\text { in Higher Education and } \\
\text { Organisations }\end{array}$ & $\begin{array}{l}\text { - Extensive survey of the challenges for adult education in a knowledge-based } \\
\text { society } \\
\text { - Shows how knowledge management can be of use in educational practice } \\
\text { - Provides case studies and best practices of new methods experimented "in } \\
\text { the field" }\end{array}$ \\
\hline $\begin{array}{l}\text { 9.Knowledge Management and } \\
\text { Industry 4.0: New Paradigms for } \\
\text { Value Creation }\end{array}$ & $\begin{array}{l}\text { - Provides evidence on how Industry } 4.0 \text { and KM interact to create value } \\
\text { - Highlights changes in value chain relationships and activities due to new } \\
\text { technologies } \\
\text { - Presents modern conceptual frameworks and a road-map for new innovation } \\
\text { strategies }\end{array}$ \\
\hline
\end{tabular}

Furthermore, Table 1 reveals the use of a wide variety of research methods ranging from traditional literature reviews, through scholars' personal views and opinions, to empirical surveys and formal case studies. Overall, these results point to gradual change in approaches to KM research from conceptual to performative which suggest the field's progression towards maturity.

\section{Discussion}

This section analyses and interprets empirical data from the survey of the IAKM members' collaborative knowledge development activities. Based on the examination of the community's outcomes and contributions to the KM academic body of knowledge and its delivery to the wider context of KM researchers and practitioners, it can be said that the Association has proved to be a successful scientific CoP, and it has really enabled fruitful interactions among its members which resulted in an enhanced process of collaborative knowledge building. The research also sought to establish how the dynamics of these interactions evolved, and what structural elements may have influenced this.

As mentioned, the findings suggest that IAKM is really a successful scientific CoP, as is evidenced by the high percentage of collaborating members ( $66 \%$ members), collaborations not limited to colleagues of the same country but also international ( 25 countries from 5 continents), prime focus on research ( $72 \%$ activities), steady growth over time (activity increase by 5 times), and the number of scientific outcomes produced. Apparently, the community contributed significantly to the KM academic body of knowledge and its delivery to KM practitioners. This is also evidenced in the comprehensive coverage of the book series topics and issues across the entire KM domain, in a variety of contexts and serving different classes of stakeholders. It also results from the balanced study of theoretical concepts and their empirical examination in practice. Most importantly, the community contributed to the recognition and progress of KM as a discipline by developing KM's distinctive intellectual core, by extending its interdisciplinary reach and by providing highly relevant lessons learnt to practitioners. All this testifies that the model of open scientific CoP that IAKM represents can favour this role in promoting the development of the scientific discipline. 
An important point to notice is that collaborative knowledge building mainly involved dyads (60\%) or triads (15\%) of members. This is comparable with earlier findings reported by Handzic (2015) regarding the number of co-authors publishing in KM journals. This may signal that, on the one hand, the preferred interactions for collaborative knowledge creation are still between 2 or 3 people (probably for the reason of efficiency and focalisation) as it normally occurs in this scientific field. In addition, as was also found in previous studies, there is a greater number of collaborations among members of the same geographical area (e.g., European countries, and sometimes more local areas, e.g., Romania, or even the same institutions - like in the case of a Chinese university). Here, probably, cultural proximity still mattered.

On the other hand, an important result of our analysis is that an effective scientific CoP can also really facilitate networking between large groups of scientists across universities, countries, and continents, which are generally more complex to build up: the survey also shows some collaborative activities involving large and very large number of members (around $25 \%$ of collaboration involve 4 or more members, very often of different countries and areas). It may therefore be argued that the climate of trust and mutual acquaintance that members were able to create over time in IAKM can favour collaborative knowledge building in large groups across nations and cultural domains.

With respect to significant structural elements influencing IAKM dynamics, this study discovered that some people ( 3 in particular) played a key role in steering IAKM's current course: the founding president of IAKM, who managed to attract a group of volunteers and enthusiasts who established a core KM community, another founding member, whose extensive international collaborations across continents contributed substantially to IAKM's expansion, and the current president, whose mobilising activities contributed to significant enlargement of the community especially in a local area (i.e. through his own nation). Therefore, their role could have been favoured by different elements: for two of them, it may be their exposure, due to their formal role in the Association; for the third person, it was probably the personal popularity which counted. In any case, it is important to notice that, although IAKM is a free CoP where any member can propose collaborative activities to others, the presence of some particularly active members can function as "glue" and can, especially, boost collaboration processes in larger groups. The most effective collaborative knowledge building processes, in substance, may require some pivotal nodes in the CoP, whose role will emerge over time thanks to their proactive attitude, and not necessarily thanks to a formal role that is assigned to them.

In addition, the analysis identified several subgroups where people collaborate more intensively with one another than with the rest of the community. This also suggests that scientific CoPs can operate successfully if they are let free to adapt dynamically to the complex structure of interactions that develop dynamically over time, based on the specific interests, attitudes, and capabilities of members.

\section{Conclusions}

This paper reported the results of a study aimed at examining IAKM as a case of scientific CoP based on its collaborative knowledge building activities and their contributions to the body of KM knowledge. The main findings revealed that a CoP can allow wide geographical-spread, large-sized and research-focused collaborations between members, with a growing trend over time. All this indicates that a scientific CoP can really have a central role in a successful research community. In addition, the findings identified that interactions among members follow dynamic paths due to specific contingencies, attitudes, and interests of members, that may tend to aggregate into different subgroups within IAKM, where interactions become more frequent and intense. This suggests that scientific CoPs can operate successfully if they are let free to operate as complex dynamic structures in the frame of a light formal configuration. Finally, the findings indicated important influencing of some leading roles, but also ordinary members. This implies that there may be some pivotal nodes in the community, especially capable of attracting members to large collaborative knowledge building activities, but the active life of the community must count on the active participation of many individual members for pushing its progress.

The case study shows a healthy interest in the KM discipline, as is indicated by the growing IAKM membership and the number of scientific outcomes that this CoP has apparently made it possible to produce. This statement contrasts earlier reports noting a decline in the volume of yearly studies on KM topics since 2015 (Serenko, 2021). Therefore, it is confirmed that participating in a scientific CoP like IAKM can really be beneficial for members, because it can boost collective knowledge building and, by this way, scientific production even higher 
than the average of scholars in the same field. While the extent of IAKM members' collaboration may depend on local connections and opportunities, the chance to reach and work with diverse individuals and groups may stimulate creativity, ensure effective use of expertise, expedite scientific discovery, enhance research visibility, avoid duplication, and enable knowledge transfer to less developed areas or scientific communities. In summary, all this suggests that a scientific CoP can really have a significant role in the production of scientific knowledge.

\subsection{Implications for research and practice}

The paper indicates that seeing a scientific association as a CoP can be useful for understanding their functioning. In addition, it opens a new field of study for KM research, because scientific associations, although they are a key element in science, have never been explicitly treated as CoPs.

This study shows how collaborative knowledge building can really develop within a scientific CoP and demonstrates that while knowledge creation is an individual cognitive process, knowledge amplification and development represents a social process, where a favourable organisational setting plays an essential role. Generally intended as social structures that can stimulate knowledge sharing and knowledge building due to their capacity of lowering the psychological barriers between participants, in practice CoPs can actually stimulate or slow down the dynamics of knowledge building depending on the specific conditions that develop in them, and that can only in part depend on their formal structure or management functions (which remains important as the general frame) but is also influenced by the active role played by its participants.

This study can also provide an opportunity for reflecting on the history of IAKM as a pointer for defining its future agenda. In addition, it can provide general lessons for creating scientific associations as effective CoPs and for developing proper methods for their management in the best way so that their capability as a platform for social interaction, knowledge exchange and mutual learning can be enhanced.

\subsection{Limitations}

While the above reported findings shed some light on the questions of interest to this study, they should be interpreted with caution due to some limiting factors. Firstly, since not all members responded to the survey, it is possible that some collaborations were not recorded. Secondly, only collaborations among IAKM members were analysed in this study. A much fuller picture of IAKM could be obtained by examining the trend of collaborative activities with non-members. Also, data were collected only for the period of 2011-2020, and some members started their collaboration much earlier. Therefore, it would be important to clearly detect the cases where the IAKM membership really improved the collaboration capability of scholars. In addition, the community's contributions to knowledge building were assessed solely based on its book series. Other collaborative publications in conference proceedings and journals could add to the accumulated significant work. Finally, it must be considered that the authors are also members of IAKM, which surely facilitated data collection but may also have led to some bias in the analysis. Overall, future research is necessary to eliminate these limitations and extend this current line of research.

\section{References}

Alamantariotou, K., Lazakidou, A., Topalidou, A., Kontosorou, G., Tsouri, M., Michel-Schuldt, M., \& Samantzis, C. (2014). Collective Intelligence for knowledge building and research in communities of practice and virtual learning environments: a project experience. International Journal of Health Research and Innovation, 2(1), 51-64.

Ali, A.A., Panneer Selvam, D.D.D., Paris, L. and Gunasekaran, A., 2019. Key factors influencing knowledge sharing practice and its relationship with organizational performance within the oil and gas industry. Journal of Knowledge Management, 23(9), 1807-1837.

Andriessen, D., 2008. Stuff or love? How metaphors direct our efforts to manage knowledge in organizations. Knowledge Management Research \& Practice, 6(1), 5-12.

Bolisani, E. and Bratianu, C., 2018. Emergent knowledge strategies: Strategic thinking in knowledge management. Cham: Springer International Publishing.

Bolisani, E. and Handzic, M. (2015) (Eds.). Advances in knowledge management: Celebrating twenty years of research and practice. Cham: Springer International Publishing.

Bolisani, E. and Scarso, E. (2014). The place of communities of practice in knowledge management studies: a critical review. Journal of knowledge management, 18(2), 366-381.

Bratianu, C., 2014. Intellectual capital of the European universities. In Dima, A.M. (Ed.). Handbook of research trends in European higher education convergence, pp. 24-43. Hershey, NY: IGI Global.

Bratianu, C. and Bejinaru, R., 2019. The theory of knowledge fields: A thermodynamics approach. Systems, 7(2), 20, 1-12, doi: $10.3390 /$ systems 7020020 . 
Bratianu, C. and Bejinaru, R., 2020. Knowledge dynamics: A thermodynamic approach. Kybernetes, 49(1), 6-21, doi: 10.1108/K-02-2019-0122.

Briskin, A., Erickson, S., Ott, J. and Callaman, T., 2009. The power of collective wisdom and the trap of collective folly. San Francisco, CA: Berrett-Koehler Publishers.

Chee, Y.S., 1996. MIND BRIDGES: A distributed, multimedia learning environment for collaborative knowledge building. International Journal of Educational Telecommunications, 2(2/3), 137-153.

Gilbert, N.J. and Driscoll, M.P., 2002. Collaborative knowledge building: A case study. ETR \& D, 50(1), 59-79.

Goleman, D., 2007. Social intelligence: The new science of human relationships. New York, NY: Bantam.

Guimerà, R., Uzzi, B., Spiro, J., \& Amaral, L. A. (2005). Team assembly mechanisms determine collaboration network structure and team performance. Science (New York, N.Y.), 308(5722), 697-702.

Haig, M., 2003. Brand failures: The truth about the 100 biggest branding mistakes of all time. London: Kogan Page.

Handzic M. (2015) A descriptive analysis of knowledge management research: Period from 1997 to 2012. In Bolisani, E. \& Handzic, M. (Eds.). Advances in Knowledge Management: Celebrating 20 years of research and practice, Knowledge Management and Organisational Learning Series (Vol.1), Cham: Springer International Publishing.

Hardwick, J., Anderson, A. R., \& Cruickshank, D. (2013). Trust formation processes in innovative collaborations: Networking as knowledge building practices. European Journal of Innovation Management, 16(1), 4-21.

Hensher M, Kish K, Farley J,Quilley S, Zywert K (2020). Open knowledge commons versus privatized gain in a fractured information ecology: lessons from COVID-19 for the future of sustainability. Global Sustainability, 3(e26), 1-5.

Hmelo-Silver, C.E., 2003. Analyzing collaborative knowledge construction: Multiple methods for integrated understanding. Computers \& Education, 41, 379-420.

Hmelo-Silver, C.E. and Barrows, H.S., 2008. Facilitating collaborative knowledge building. Cognition and instruction, 26, 4894.

Hong, J., Heikkinen, J. and Blomqvist, K., 2010. Culture and knowledge co-creation in R\&D collaboration between MNCs and Chinese universities. Knowledge and Process Management, 17(2), 62-73.

Jakubik, M., 2008. Experiencing collaborative knowledge creation process. The Learning Organization, 15(2), 5-25.

Kali, Y., 2006. Collaborative knowledge building using the design principles database. Computer-Supported Collaborative Learning, 1, 187-201.

Kahneman, D., 2011. Thinking, fast and slow. New York, NY: Farrar, Straus and Giroux.

Kirkman, B.L., Mathieu, J.E., Cordery, J.L., Rosen, B. and Kukenberger, M., 2011.Managing a new collaborative entity in business organizations: Understanding organizational communities of practice effectiveness. Journal of Applied Psychology, 96(6), 1234-1245.

Lave, J. and Wenger, E. (1991), Situated learning: Legitimate peripheral participation. Cambridge: Cambridge University Press.

Li, Q., 2006. Knowledge-building in an online environment: A design-based research study. Malaysian Journal of Distance Education, 8(2), 1-26.

Liu, H. L., Zhu, L., Chen, Y., \& Huang, R. (2005). A Research about Collaborative Knowledge Building through Interaction Analysis. Open Education Research, 11(2), 31-37.

Murray, T., 2006. Collaborative knowledge building and integral theory: On perspectives, uncertainties, and mutual regard. Integral Review, 2, 210-264.

Nahyan, M.T., Sohad, A., Hawas, Y. and Fildes, B., 2019. Communication, coordination, decision-making and knowledge sharing: A case study in construction management. Journal of Knowledge Management, 23(9), 1764-1781.

Nissen, M.E., 2006. Harnessing knowledge dynamics: Principled organizational knowing \& learning. London: IRM Press.

Nonaka, I., 1994. A dynamic theory of organizational knowledge creation. Organization Science, 5(1), 14-37.

Nonaka, I. and Takeuchi, H., 1995. The knowledge-creating company: How Japanese companies create the dynamics of innovation. Oxford: Oxford University Press.

Nonaka, I. and Takeuchi, H., 2019. The wise company: How companies create continuous innovation. Oxford: Oxford University Press.

Nonaka, I., Toyama, R., and Hirata, T., 2008. Managing flow: A process theory of the knowledge-based firm. Houndmills: Palgrave Macmillan.

O'Dell, C. and Hubert, C., 2011. The new edge in knowledge: How knowledge management is changing the way we do business. New York, NY: John Wiley \& Sons.

Oshima, J., Oshima, R., \& Matsuzawa, Y. (2012). Knowledge Building Discourse Explorer: a social network analysis application for knowledge building discourse. Educational technology research and development, 60(5), 903-921.

Petrides, L.A. and Nodine, T.R., 2003. Knowledge management in education. Half Moon Bay, CA: Institute for the Study of knowledge management in education.

Philip, D. (2010). "Social network analysis to examine interaction patterns in knowledge building communities". Canadian Journal of Learning and Technology/La revue canadienne de l'apprentissage et de la technologie, 36(1),

Putambekar, S., 2006. Analyzing collaborative interactions: divergence, shared understanding and construction of knowledge. Computers \& Education, 47, 332-351.

Scardamalia, M. and Bereiter, C,, 2003. Knowledge building. In Guthrie, J.W. (Ed.). Encyclopedia of Education (pp.13701373). New York, NY: McMillan References.

Serenko, A., 2021. A structured literature review of scientometric research of the knowledge management discipline: a 2021 update, Journal of Knowledge Management, February 2021. 
Singh, G., Hawkins, L. and Whymark, G., 2007. An integrated model of collaborative knowledge building. Interdisciplinary Journal of Knowledge and Learning Objects, 3, 85-105.

So, H.J., Seah, L.H. and Toh-Heng, H.L., 2010. Designing collaborative knowledge building environments accessible to all learners: Impacts and design challenges. Computers \& Education, 54, 479-490.

Stacey, R.D., 2001. Complex responsive processes in organizations: Learning and knowledge creation. London: Routledge. Stahl, G., 2000. A model of collaborative knowledge-building. In Fishman, B. \& O'Connor-Divelbiss, S. (Eds.). Fourth International Conference of the Learning Sciences (pp. 70-77). Mahwah, NJ: Erlbaum.

Wenger, E., 1998. Communities of practice: Learning, meaning, and identity. Cambridge: Cambridge University Press.

Wenger, E., McDermott, R. and Snyder, W.M., 2002. A guide to managing knowledge: Cultivating communities of practice. Boston, MA: Harvard Business School Press.

Yin, R.K., 1994. Case Study Research: Design and Methods, Thousand Oaks: Sage Publications.

Zohar, D. and Marshall, I., 2004. Spiritual capital: The wealth we can live by. San Francisco, CA: Berrett-Koehler Publishers. 